\title{
IBS Optimisation at Wet Areas to Solve Leaking
}

\author{
Nurul Asra Abd. Rahman'1 Zainab Mohmad Zainordin ${ }^{1}$ Suryani Ahmad ${ }^{2}$ \\ ${ }^{1}$ Centres of Studies for Construction, Universiti Teknologi MARA, 40450 Shah Alam, Selangor, Malaysia. \\ 2 Department of Building, Universiti Teknologi MARA, 32610 Bandar Sri Iskandar, Perak, Malaysia. \\ asra@salam.uitm.edu.my
}

\begin{abstract}
Hybrid construction method with In-situ reinforced concrete (IRC) for wet areas in predominantly precast concrete (PC) buildings to overcome leakage problem is a setback for full IBS adoption. Various options explored to reduce IRC at toilet only to discover the answer is possible within the existing parameters of IBS. The proposal adopts composite construction comprised of metal permanent formwork and ISC casting for toilet floor while PC components remained as buildings structural framing system. This proposal combined different elements of IBS systems offers all the advantages associated with IBS; minimize wastages, better quality, shorter construction period and minimized unskilled workers.
\end{abstract}

Keywords: Industrialised Building Systems; Hybrid technology; Pre-Cast Structure; Leakage at Wet Area.

eISSN: 2398-4279 @ 2017. The Authors. Published for AMER ABRA by e-International Publishing House, Ltd., UK. This is an open-access article under the CC BY-NC-ND license (http://creativecommons.org/licenses/by-ncnd/4.0/). Peer-review under responsibility of AMER (Association of Malaysian Environment-Behaviour Researchers), ABRA (Association of Behavioural Researchers on Asians) and cE-Bs (Centre for EnvironmentBehaviour Studies), Faculty of Architecture, Planning \& Surveying, Universiti Teknologi MARA, Malaysia. https://doi.org/10.21834/ajqol.v2i8.67 


\subsection{Introduction}

Industrialised Building system (IBS) is defined as a construction process of a building system that utilises prefabricated components and on-site installation. Improve perception on adoption of IBS in Malaysia is attributed by initiatives by the federal government through IBS roadmap programs to modernize the construction industry and to reduce the conventional in-situ method of construction. The adoption of IBS offers valuable advantages such as the reduction of unskilled workers; fewer wastages; less volume of site materials; improve site cleanliness; reduce environmental pollution; better quality control; promote site safety practice and reduce construction time. Structural classification under IBS roadmap falls into five (5) main categories namely: precast concrete framing/panel and box systems; formwork systems; steel framing systems; prefabricated timber framing systems and blockwork systems. (Mohammad M.F., 2013). Precast Concrete (PC) framing system, panel and box system that fully utilize prefabrication technology fit the definition of IBS as compared to formwork systems which still involve on wet trades site activities. A case study by Bari et al. (2012) shows that prefabrication technology of PC framing/panels and block-work system if conceptualized at early design stage can provide significant advantages over conventional IRC such as reduction in construction time by $35 \%$, less skilled labour requirements and construction cost savings of more than $10 \%$, and improved quality control. Because of the advantages, IBS essentially promotes sustainable construction (SC) whereby building construction activities are responsible for creating and maintaining a healthy environment and human health through efficient of resources. The SC process should start from planning stage until the building is handed over to the client (Isnin et al. 2013).

One of the limitations of adopting PC is water seepage problem. A survey by Building and Construction Authority (BCA) Singapore in 2003 BCA (2014), shows that PC joints are the weakest links in ensuring water tightness which includes joints between precast elements as well as joints between precast elements and other fittings (Kamar et al. 2007). Leaking also occurs through construction joints and cold joint because the different cast of concrete will not bond properly due to different stage of setting and hardening times. Unfilled joints between PC floor panels need IRC topping to close the gap and to achieve flat floor surface, thus creating cold joints between precast elements and in-situ topping. Natural cement shrinkage during building life cycle will further widen the cold joints marginally and water leaks through this open joints. The leaking problem is more prevalent in wet areas such as toilets, balconies, pantries since the areas are constantly exposed to water. Long exposure of concrete structures to dampness will deteriorate building structural integrity.

It is a common practice to adopt a hybrid method within the same building with the IRC used for wet areas and PC used for the remaining areas. Hybrid system or mixed system, according to Lachimpandy et al. (2011), is considered as an amalgamation of IBS and the conventional construction. Conventional in-situ system, despites being the least efficient, is by far the most widely used in Malaysia. IBS is still at the infancy stage and is 
not preferred by most contractors. Therefore, adoption of a mixed system is seen as an intermediate construction method that can slowly reduce the gap between IBS and conventional construction. The initial objective of this research is to develop a revolutionary jointing system in PC structure that can solve leaking problems suitable for use in wet areas in PC buildings. This is to reduce or eliminate the use of IRC method of construction and increase IBS usage.

\subsection{Literature Review}

A literature review of existing research materials is to establish variables related to the research topics by exploring issues on existing methods adopted to alleviate leaking in PC, causes of leaking in PC and outlining possible solution to leaking problem in PC.

\section{Existing Methods of sealing joints in Precast Concrete}

Concrete joints are designed to help alleviate contraction, expansion, cracking, and vertical movement of concrete. Concrete joints are also used between different stages of concrete casting. Joints between PC components provide physical separation between each panel which is necessary because PC components have to be of a manageable size so that they can be manufactured in the factory, transported on the public road and erected on the site. Once installed, the joints between PC panels can be left open, closed with sealants or covered with concrete toppings.

\section{a) Sealant materials}

Sealants are typically designed or applied to resist hydrostatic forces at PC joints to provide a watertight seal (Box Culvert 2013). Sealing of PC joints is to prevent ingress of water and air into buildings. Connections between precast concrete components can be in simple butt joints, lap joints or tongue, and groove joints. Sealing methods between PC joints can be open-drained, face-sealed and compression-sealed (NPCAA - 2012). Among various types of sealants, polyurethane and single component silicone are two most commonly used sealant materials for sealing joints between PC components (SIKA, Brochures 2010-2014). Sealant does not bond properly on wet and porous surfaces like concrete and usually needs base primers as adhesive to avoid premature failure (CCPCl 2010). Sealants materials have limited life span and it varies under different climatic conditions. Most manufacturers offer limited product warranties on all their sealant products, usually for a specific period (5-10 years) and it comes with strict technical conditions. Sealant works best under compression, therefore, it is suitable for use during vertical stacking application whereby the self-weight of PC upper panels compresses the sealants on the PC lower panels. Common uses of sealant for horizontal application in PC components are as expansion joints and contraction joints (NPCAA - 2012). The above observations show that 
the initial objective of this research to develop a revolutionary joints and sealant systems may not offer long term solution to solve leaking problem in PC structure.

\section{b) In-situ Reinforced Concrete (IRC) Topping}

The sealant is not recommended to seal joints between PC floor panels inside buildings because the narrow gaps of 1 to $5 \mathrm{~mm}$ between each panel make it impossible to apply any types of sealants effectively. IRC topping above the PC slabs is part of the structural requirement to resist lateral movement. It also functions to close gaps between joints and to create flat floor surface. Mechanical and electrical services can be embedded into the insitu structural topping (BCA, Singapore 2012). Unfortunately, this method is susceptible to cracks due to the formation of cold joints between PC slab and in-situ topping resulted from different stages of concrete casting. This factor causes the leaking problem in PC and therefore not suitable for use at toilet areas.

\section{Determination on Causes of leaking for toilet in Precast Concrete Structure}

In consensus, consistent with site observations and findings by Rahman et al (2013) and Chew et al. (2014), all stakeholders agreed that most common causes of leaking for toilets and wet areas in concrete frame building, regardless of PC or IRC constructions are leaking through cracks, leaking through pipe penetration, leaking through cold joints and Poor waterproofing workmanship.

Based on site observations and consistent with findings by Li et al, (2009) and Kamar et al. (2007), stakeholders in consensus agreed that the leaking problems for toilets and wet areas are more prevalent in PC structure as compared to IRC structure due to; a) structural cracks caused by movement between PC components, b) cold joints between PC slab and IRC topping, c) hairline cracks of in-situ concrete topping and, d) sanitary pipe sleeves that penetrated through preformed openings of PC slab. The pipes are placed and cast at later stage of construction together with in-situ concrete topping

According to CIDB, previous attempts to use PC slab for toilets in PC frame building had been unsuccessful. It was observed that PC structure is not rigid and is always prone to cracks when subjected to structural movement caused by imposed loads during the buildings natural life cycle. Due to the formation of cracks by the structural movement, revolutionized jointing system of PC components, as originally intended may not offer longterm or permanent solution to the leaking problem.

According to Rahman et al. (2013) in Malaysian context, IRC is still the preferred method of construction for toilets and wet areas in PC structure with two (2) most common approaches namely; a) The whole toilet supporting structural elements full IRC construction or b) Hybrid method where the columns and lower half of beams remain as PC while only the top of beam and slab adopt IRC. The use of IRC method of construction for toilets in a PC frame building often slow down the progress of work, increase material wastages, produce a lower quality of work and increase man-power. Somehow, the hybrid of the two (2) systems defeats the noble intention on full IBS adoption. Therefore, another method of 
construction should be explored to maximize the IBS content. The alternative method of construction should be able to address the issues on the maximization of IBS usage and solve the leaking problem often associated with PC structure. Factors to be considered while developing the alternative methods are a) a universal toilet design suitable for PC frame buildings of different functions, b) floor slab for the toilet areas to be isolated and monolithically casted in one pour of concrete together with any pipe penetration to eliminate construction joints or cold joints and most importantly to explore usage of other IBS components among different structural categories of IBS.

\subsection{Methodology}

This research adopted meta-analysis method that combined results from multiple studies and to reduce any gaps and uncertainty. Different methodologies adopted were; 1) Interview sessions with stakeholders related to PC namely; IBS Centre, IBS manufacturers, IBS installers, and IBS consultants, 2) Literature reviews and formulation from recent and previous researches related to leaking problems in PC buildings 3) Site inspections on PC buildings that experienced leaking problems and 4) Develop a suitable system to solve leaking problem in PC to validate findings.

\subsection{Results and Discussions \\ Proposed solution to leaking problem for toilet and wet areas in precast concrete structure}

\section{Typical toilet design}

For the purpose of this research, an actual toilet layout for the main block of FSPU, UITM Shah Alam, had been adopted with some slight modifications made to the design to improve maintainability. The medium size toilets designed for both genders where male and female toilets confined to a column grid of $6 \mathrm{mx} 6 \mathrm{~m}$. A shared common service duct placed between the two toilets was for laying of sanitary and water pipes horizontally inside the service area. The pipes can be connected directly to sanitary and tap fittings, thus minimize vertical pipe penetration through the slab. All toilets' internal walls to use lightweight concrete blocks to avoid the need for secondary internal support beam. Typical toilet design is as shown in figures 1 and 2. 
Abd. Rahman, N. A., et.al. / Asian Journal of Quality of Life, AjQoL, 2(8) Oct / Dec 2017 (p.23-34)

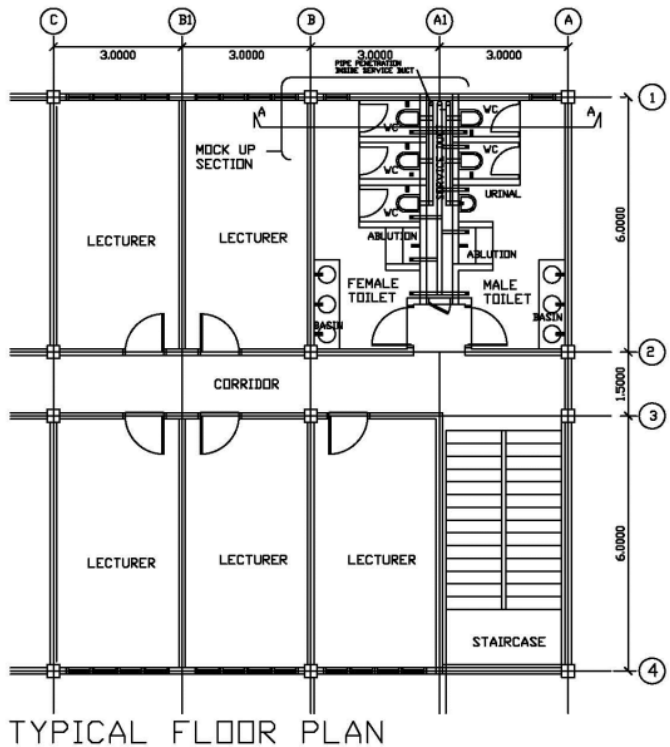

Figure 1: Floor plan of toilet design

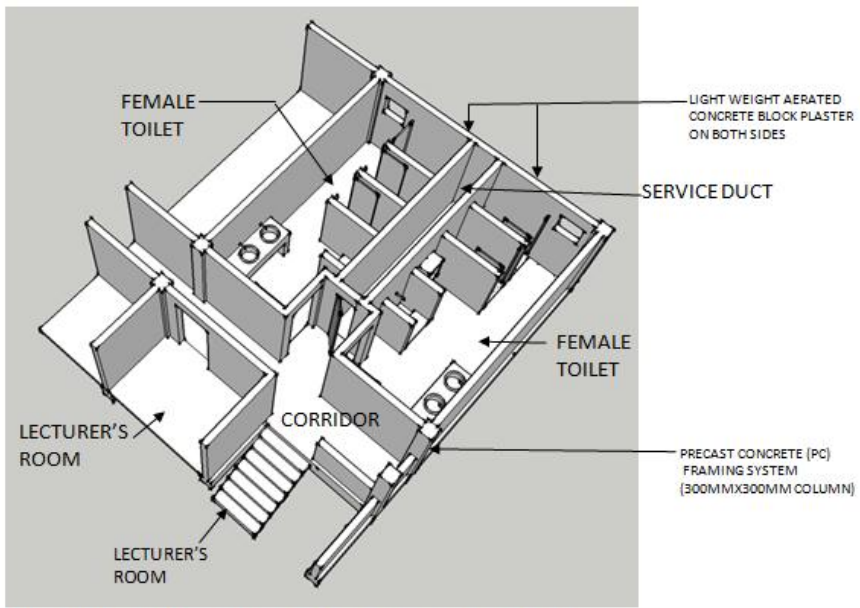

PERSPECTIVE VIEW OF TOILET DESIGN

Figure 2: Perspective view of toilet design 


\section{Possible solutions}

Based on research by Rahman et al. (2013), under an ideal circumstance of IBS application, the whole toilets should be constructed as a complete Prefabricated Toilet Units (PTU). In developed countries like Singapore and Japan, PTU is commonly used in aircraft industry, ships construction and in building construction. However, usage of PTU in Malaysian context is limited to the outdoor portable toilets. Based on IBS Centre records, no PTU had been successfully developed under mass production for commercial usage inside buildings. This is probably due to lacks of awareness and readiness of the market to adopt PTU. Public are familiar and have a strong preference for the in-situ toilet which is considered to offer greater design creativity and flexibility. Due to logistic reasons, PTU is only suitable for small to medium sized toilets and therefore not feasible for adoption at larger toilets intended for this research.

Another possible solution is to use PC panel technology whereby the whole floor slab for the toilet is treated like a concrete tray and fabricated under a controlled factory environment together with pipe sleeves and electrical conduits embedded into it. The waterproofing application and water-flooding test can be done in factory prior to delivery to site. However, logistic factor for transportation of the $6 \mathrm{mx} 6 \mathrm{~m}$ slab from the factory to site and hoisting it from the ground into the building will be a major setback. Therefore, this option is also not feasible.

\section{Final Proposal}

The final proposal that explores the use other elements of IBS structural systems is a combination of PC and metal permanent formwork system. The proposal is for the whole floor slab for the toilets within the $6 \mathrm{mx} 6 \mathrm{~m}$ column grid to be constructed using composite construction comprises of metal permanent formwork and in-situ concrete slab, PC halfbeams, and PC columns. The suitability of this proposal in term of compliance to IBS requirement and offer solution to leaking problem is based on the following observations;

a) Metal permanent formwork that can be cut to any length and shape is suitable for use in steel frame and PC frame structures (BHP Lysaght Bondek @11 web-site),

b) Steel reinforcement above the metal permanent formwork can be secured to the exposed reinforcement of perimeter PC half-beams, thus creating a monolithic system for the toilet. This can minimize possibility of structural cracks.

c) Casting of concrete above the metal permanent formwork can be in one pour, thus eliminates in-situ concrete topping and formation of cold joints.

d) Pipe sleeves and electrical conduits can be casted together with the composite floor in one monolithic system, thus reduce the possibility of leaking.

Essentially, the whole composite floor and PC perimeter half-beams offer similar characteristics as IRC method of construction without the need for temporary formwork. Elimination of temporary formwork would translate to shorter construction time, reduce 
wastages and less pollution to surrounding environment. Images of final proposal are as shown figures 3 and 4 .

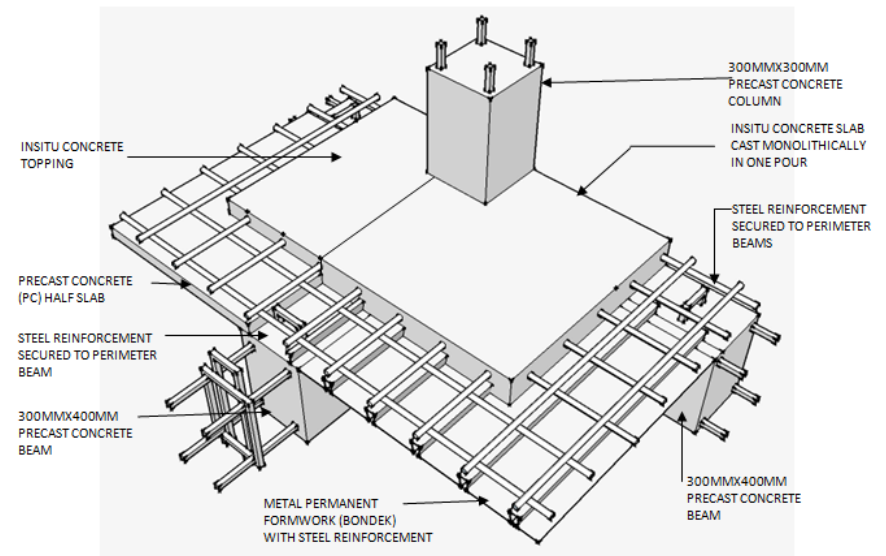

BLOW UP DETAIL OF STRUCTURAL COMPONENTS

Figure 3: Blow up detail of final proposal

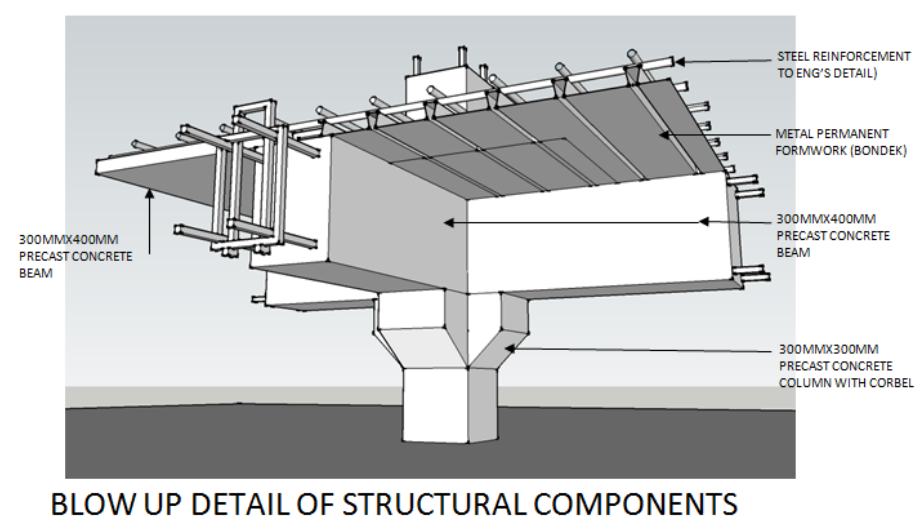

Figure 4: Blow up detail of final proposal

\section{Mock-up of proposal}

To prove the suitability of the proposal, a mock-up was constructed to conduct water flooding for testing of any possible leaking. Instead of constructing the whole $6 \mathrm{~m} \times 6 \mathrm{~m}$ 
column grid area and the immediate surrounding areas, only a small section of the final proposal was constructed as mock up. It was to focus on critical areas of possible leaking particularly at the intersection between various building elements (PC components, composite floor slab, masonry walls, in-situ toppings) and waste pipes penetration for sanitary services. Since only a small section of the proposal had been constructed as mock up, temporary masonry walls and columns had been constructed to support the PC beam, PC half slab, and metal permanent formwork. The mock-up construction strictly retained the concept and sequence of work for PC framing structure. Plan and images of mock up are as in figures 5,6 and 7 .

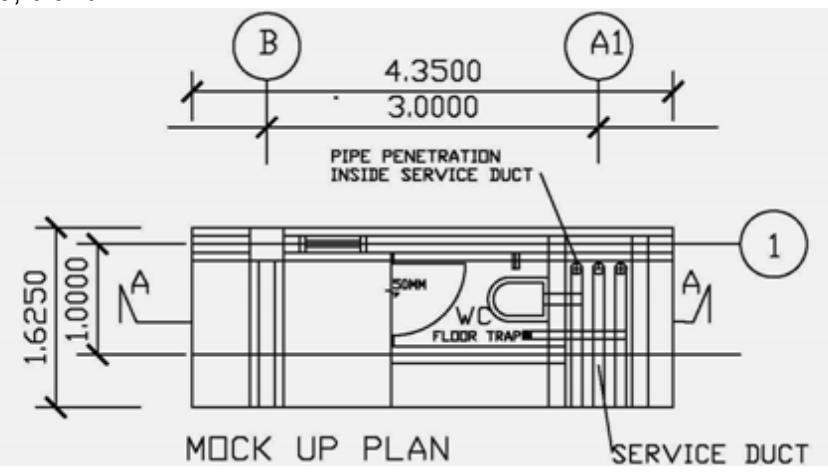

Figure 5: Floor plan of mock up

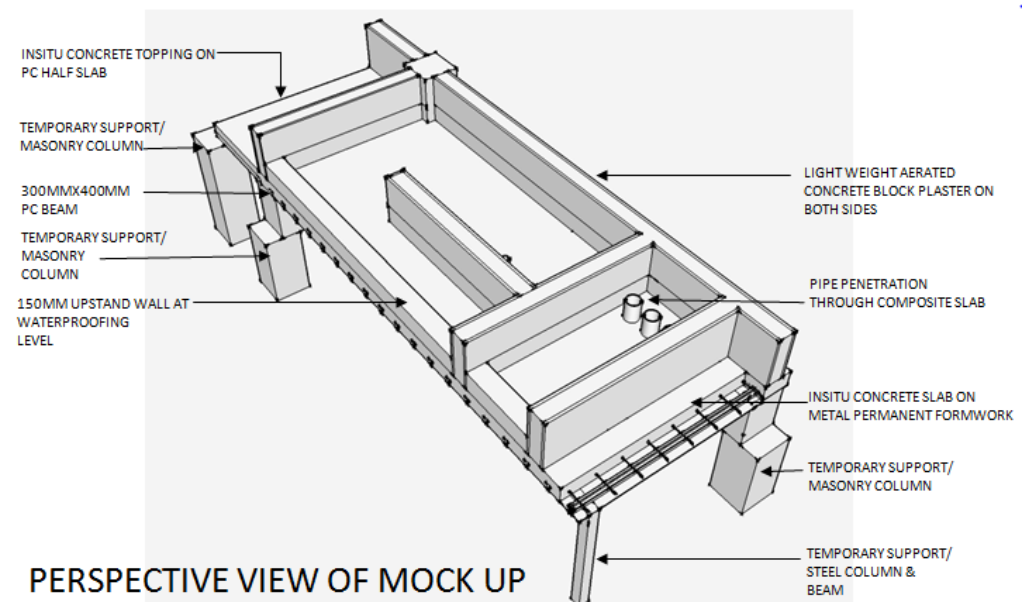

Figure 6: Image of mock up 


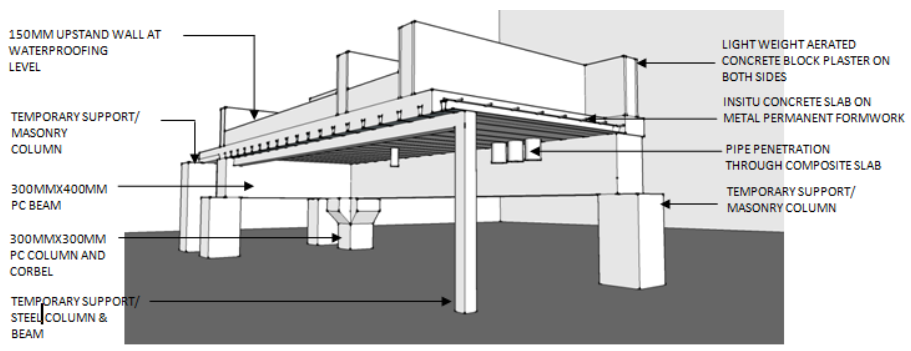

PERSPECTIVE VIEW OF MOCK UP

Figure 7: Image of mock up

\section{Observation on flooding test of mock up}

The water-flooding test was adopted to identify water-tightness against leaking whereby water was filled inside the toilet areas at $150 \mathrm{~mm}$ height to match waterproofing level. Any sign of leaking was then observed outside the flooded area for an extended period of three (3) months. This is to allow for structural movement or settlement of PC components. The mock-up was covered with two (2) layered plastic to avoid outside water from entering the flooded area and to reduce water evaporation. Observations recorded after one (1) month of flooding test showed encouraging results whereby no major structural cracks due to movement of PC components, no major hairline cracks of in-situ concrete topping, no water mark outside waterproofing area, no water drip below metal permanent formwork or through pipe penetration. This proved that the mock-up had been properly constructed. Similar results were observed at the end of the second month and third month observation period. A slight drop of water level below the $150 \mathrm{~mm}$ mark was suspected from an effect of minimal evaporation resulted from heat generated below the plastic cover. Drop in water level due to evaporation was negligible.

\subsection{Conclusion}

\section{Effectiveness of final proposal against leaking}

Based on results compiled during the three months flooding test, it can be concluded that the proposal to use metal permanent formwork as floor base of toilets in PC structure is feasible. It complied with the context of IBS requirements in Malaysia. The metal permanent formwork basically replaced PC half-slab or PC slab that also functions as permanent formwork.

This proposal that combined three (3) IBS construction systems namely; PC framing system, metal permanent formwork and modular masonry blocks offers all the advantages of IBS. However, the success of this proposal requires careful planning during the design 
stage and strict supervision during the construction stage. This is consistent with the finding by Ismail et al. (2012), which suggests that good coordination among all parties in management factors for every stage of IBS play the main role as the pulse towards the success of any IBS projects. Ismail et al. (2013) also emphasize improvement in site management system of IBS construction includes work-place, work team, safety, materials, and equipment contributes towards the success of IBS projects. For this research proposal, the coordination during design stage of toilet and construction of mock-up was crucial to ensure the effectiveness of proposal in meeting the research objectives. This is to ensure the technical aspects of the proposal as identified while developing the design are carefully monitored.

\subsection{Recommendations}

Technically, based on the flooding test result, the proposal is feasible for adoption. However, other factors such as aesthetic and financial aspects also need to be considered before actual adoption. The original objective of this research is to develop a revolutionary jointing system in PC structure to solve leaking problems for use at toilets and wet areas. However, the final proposal adopted a slightly different approach which combined different categories of IBS also met the same objective of solving the leaking problem. The adoption of this hybrid method of constructions not only promotes maximization of IBS usage but also solve leaking problem in PC structure particularly at toilets and wet areas. Most importantly, it also contributes towards achieving the main objective of IBS roadmap; to reduce dependency on unskilled foreign labour through modernization of the construction industry. Modernization of construction industry as a whole will improve the quality of work through reduction of in-situ construction activities and wet trades on site. IBS, when embraced in total, can contribute to better quality of life.

\section{Acknowledgement}

Special thanks to the Kementerian Pendidikan Malaysia (KPM) for funding this research via Research Management Institute (RMI), Development Department of Universiti Teknologi MARA.

\section{References}

Bari N.A.A, Abdullah N.A., Yusuff R., Ismail N., Jaapar A. (2012). Environmental Awareness and Benefits of Industrilized building Systems (IBS). Procedia Social and Behavioral Sciences, 50 (2012) 392-404.

Building Construction Authority (2012). Building and Construction Authority Singapore. Design Concept for Precast System. Retrieved on $6^{\text {th }}$ August 2012 from bca.gov.sg. 
Building Construction Authority (2014). Building and Construction Authority Singapore. Design of External Wall. Retrieved July 18, 2014 from http://www.bca.gov.sg

Canadian Precast-Prestressed Concrete Institute (CPPCl - 2010) - Architectural Precast Concrete Sealant Joint Guide 2010.

Chew M.Y.L., Nayanthara D.S., Tan S.S. (2014). Maintainability of Wet Areas of Non-residential Building. Structural Survey, 22(1), 39-52

Ismail F., Yusuwan N.M., Baharuddin H.E.A. (2012). Management Factors for Successful IBS Projects Implementation. Procedia Social and Behavioral Sciences, 68 (2012) 99-107.

Ismail F., Baharuddin H.E.A., Marhani M.A. (2013). Factors towards Site Management Improvement for Industrialized Building System (IBS) Construction. Procedia Social and Behavioral Sciences, 85 (2013) 43-50.

Isnin Z., Ahmad S.S., Yahya Z. (2012). Building Material Management Framework for Greener Adaptation Projects. Asian Journal of Environment-Behaviour Studies, Volume 3, Number 8, April 2012.

Kamar K.A.M., Hamid Z.A., . Ghani M.K., \& Rahim A.H. (2007). Industrialized Building Systems: Current Shortcomings and the Vital Role of R\&D. 2 ${ }^{\text {nd }}$ Quarter Master Building Publication.

Lachimpadi S.K., Pereira J.J., Taha M.R., Mokhtar M. (2012). Construction Waste Minimisation Comparing Conventional and Precast Construction (Mixed System and IBS) methods in High-rise Buildings: A Malaysia Case Study. Resources, Conservation, and Recycling, 68 (2012) 96-1-3.

Li K., Li C., Chen Z. (2009). The Influential Depth of Moisture Transport in Concrete Subject to Drying-Wetting Cycles, Cement \& Concrete Composite, 31, 693-698.

Lysaght. (2014). Structural Products. BHP Lysaght Bondek @11. Retrieved on July 18, 2014, from http://www.bluescopelysaght.com.my

Mohammad M.F. (2013). Construction Environment: Adopting IBS Construction Approach towards Achieving Sustainable Development. Procedia Social and Behavioral Science, 85 (2013) 8-15.

National Precast Concrete Association Australia (NPCAA -2012) Precast Concrete Hand Book 2012.

Precast Concrete Box Culvert Joint Sealant Guidelines. Retrieved on 30th June 2013 from www.boxculvert.com.

Rahman N.A.A., Ahmad S., Zainordin Z. (2013). Perception and Awareness of Leaking for Toilet in Pre-cast Concrete Structure. Procedia Social and Behavioral Science, 85 (2013) 61-69.

SIKA, Brochures 2010-2014 